putting two and two together

for solo piano

ian gardiner 


\section{putting two and two together}

Ian Gardiner

Slow, strangely calm

. $=42$
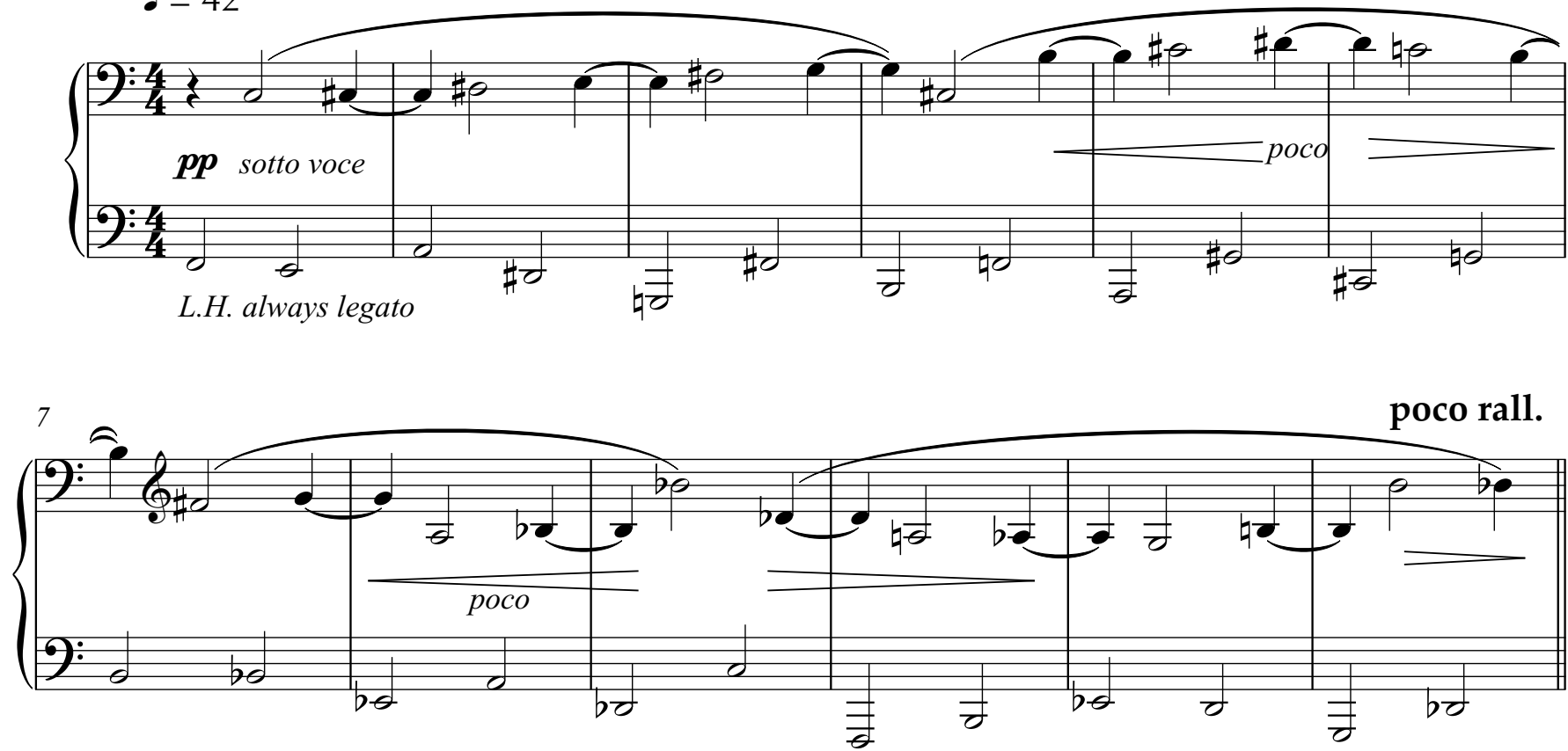

Pochissimo più mosso
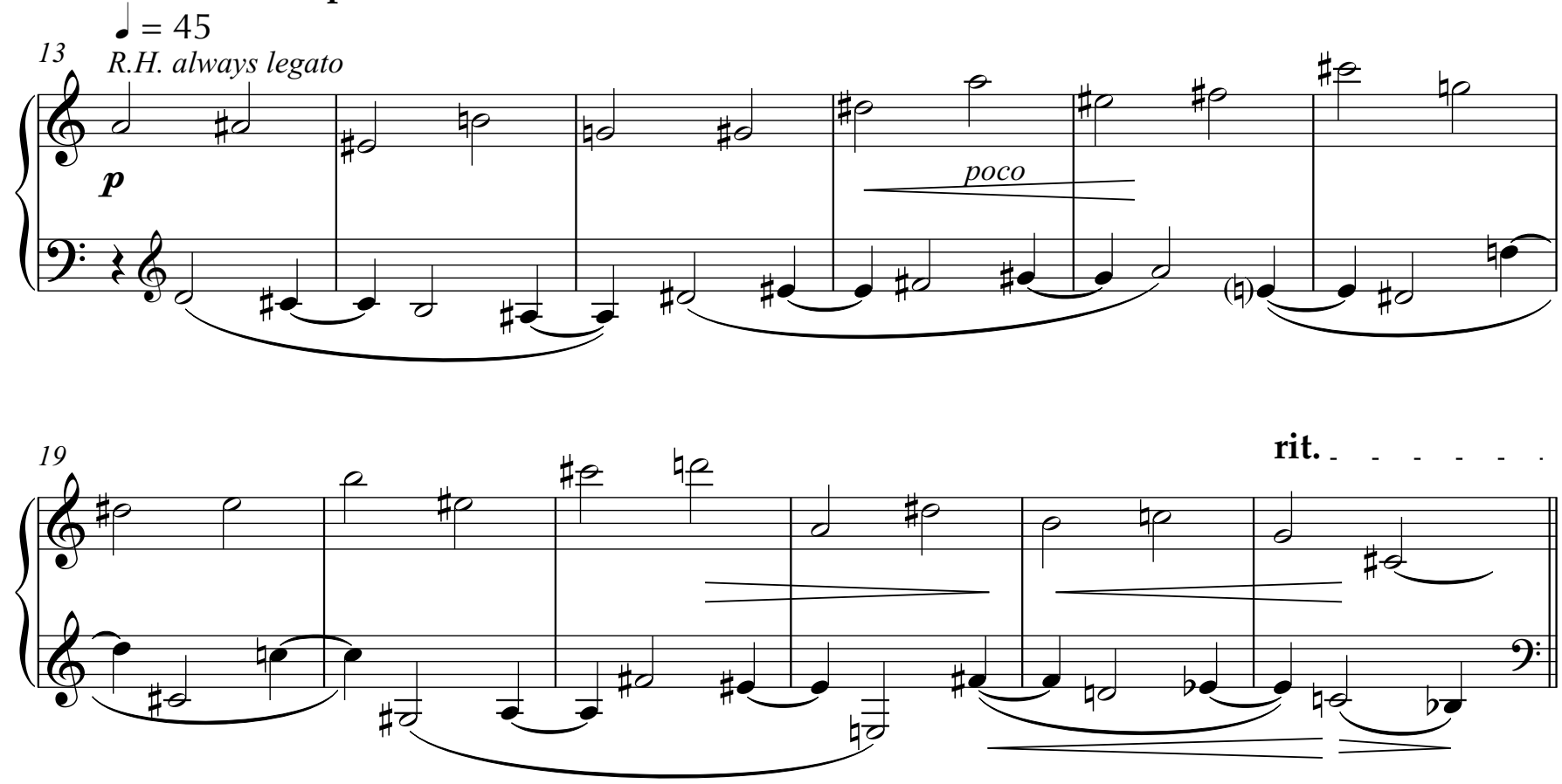
3
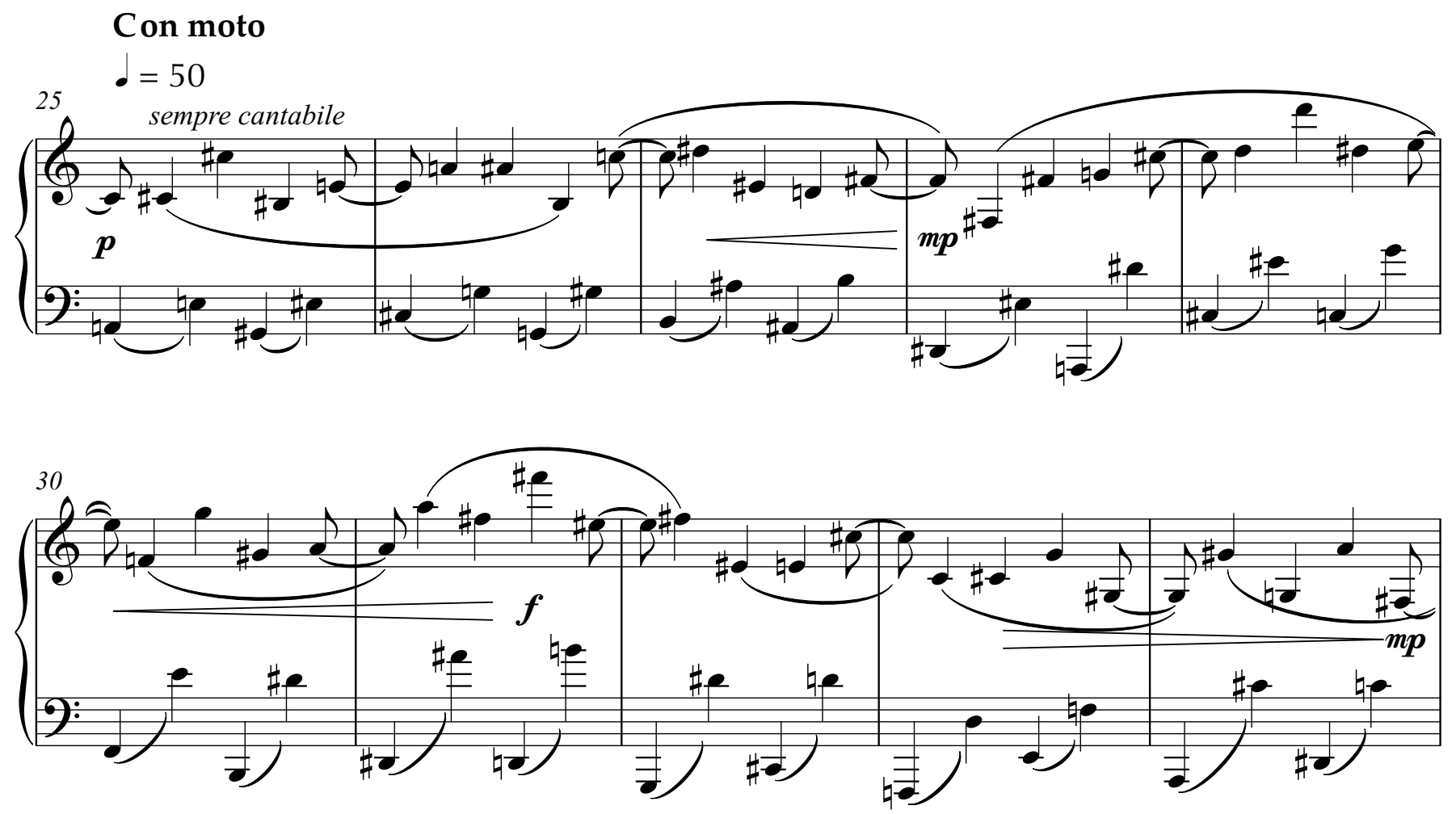

Poco piú mosso rit. -
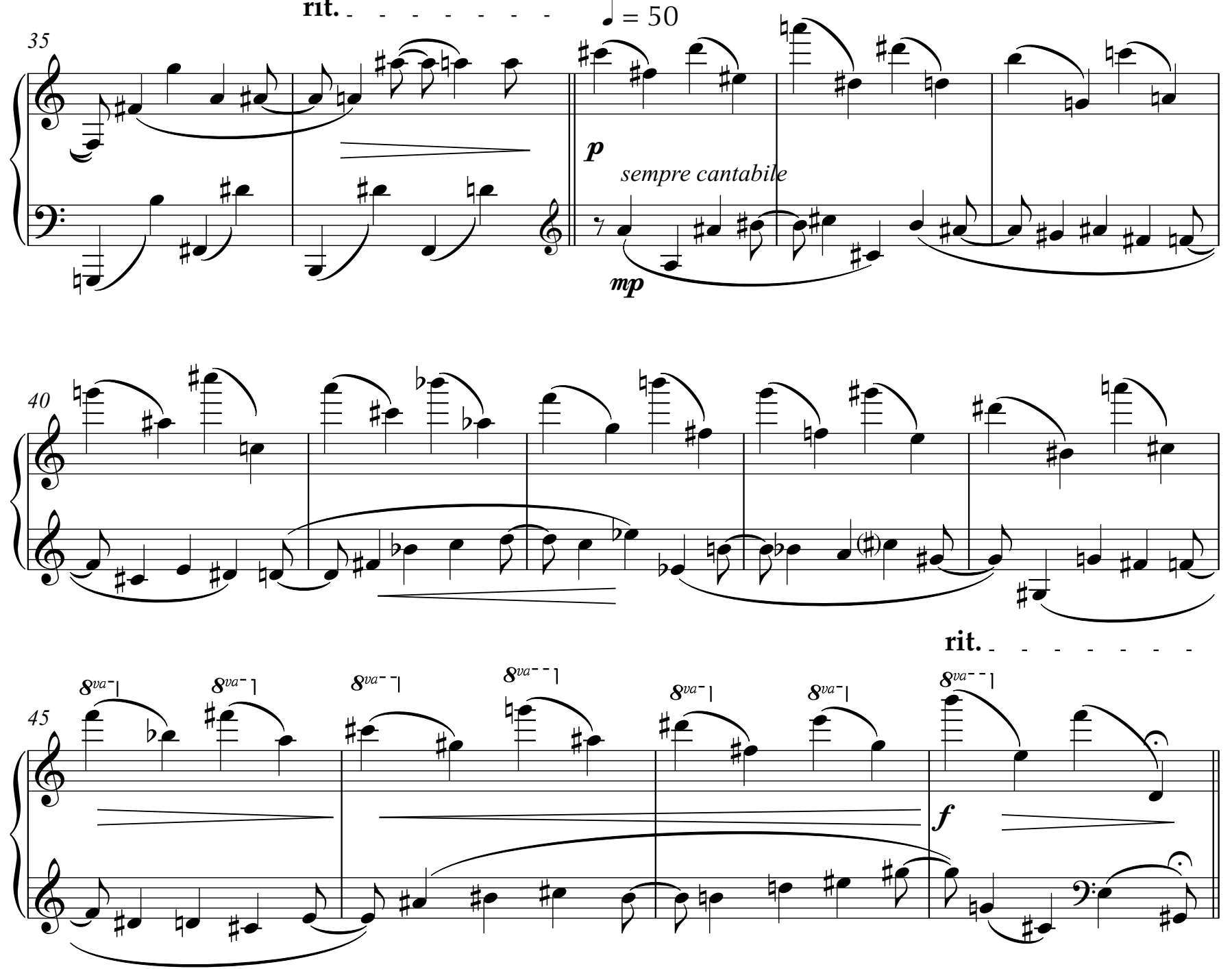
Più movimento
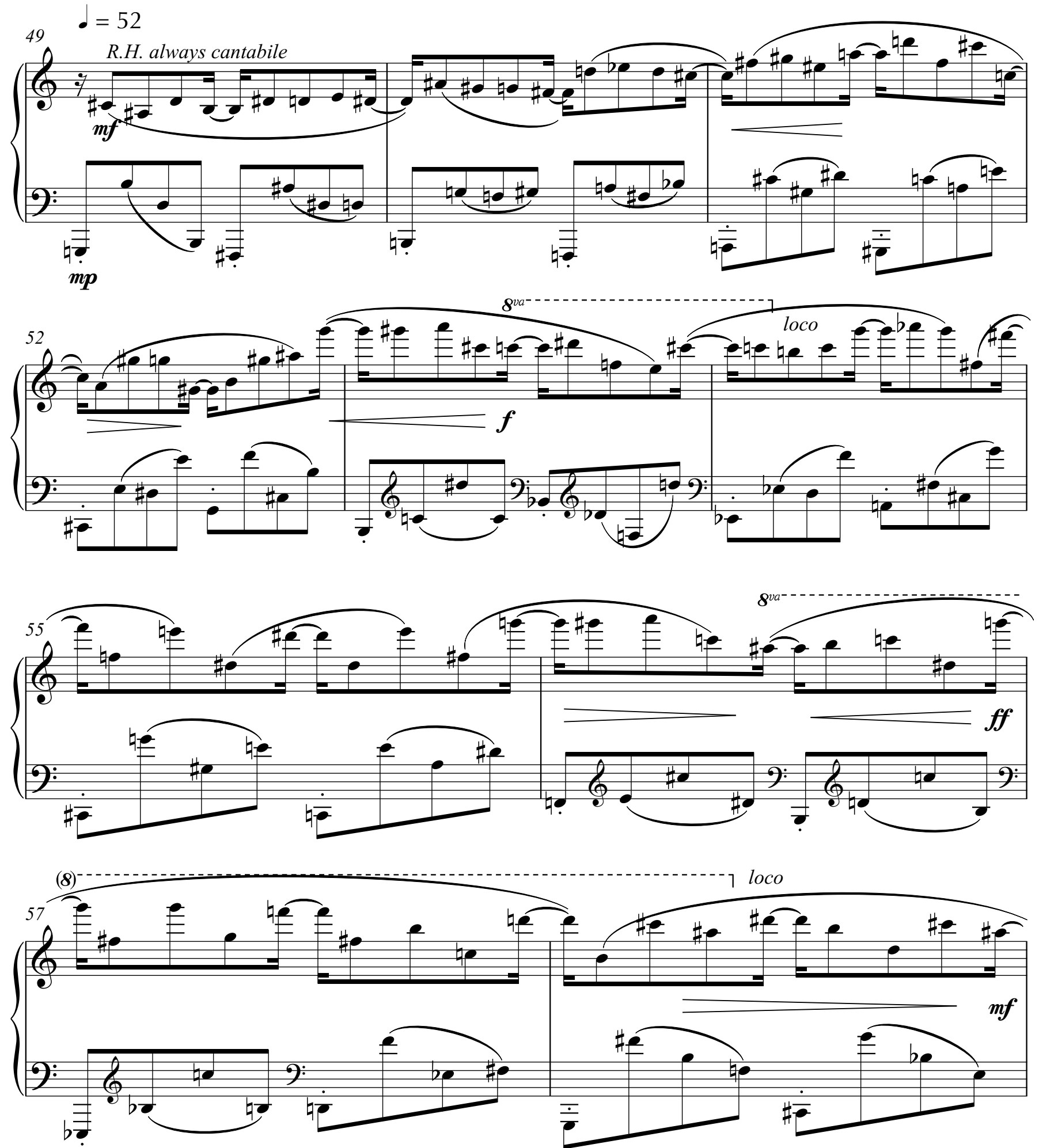

rit.

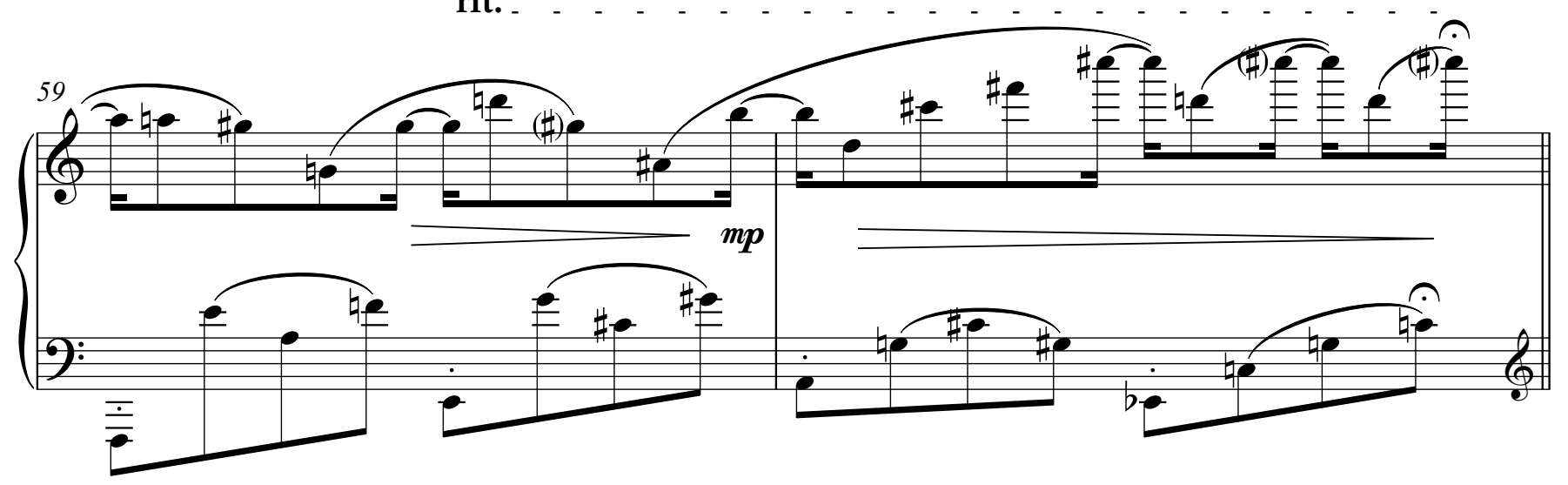


Slightly faster
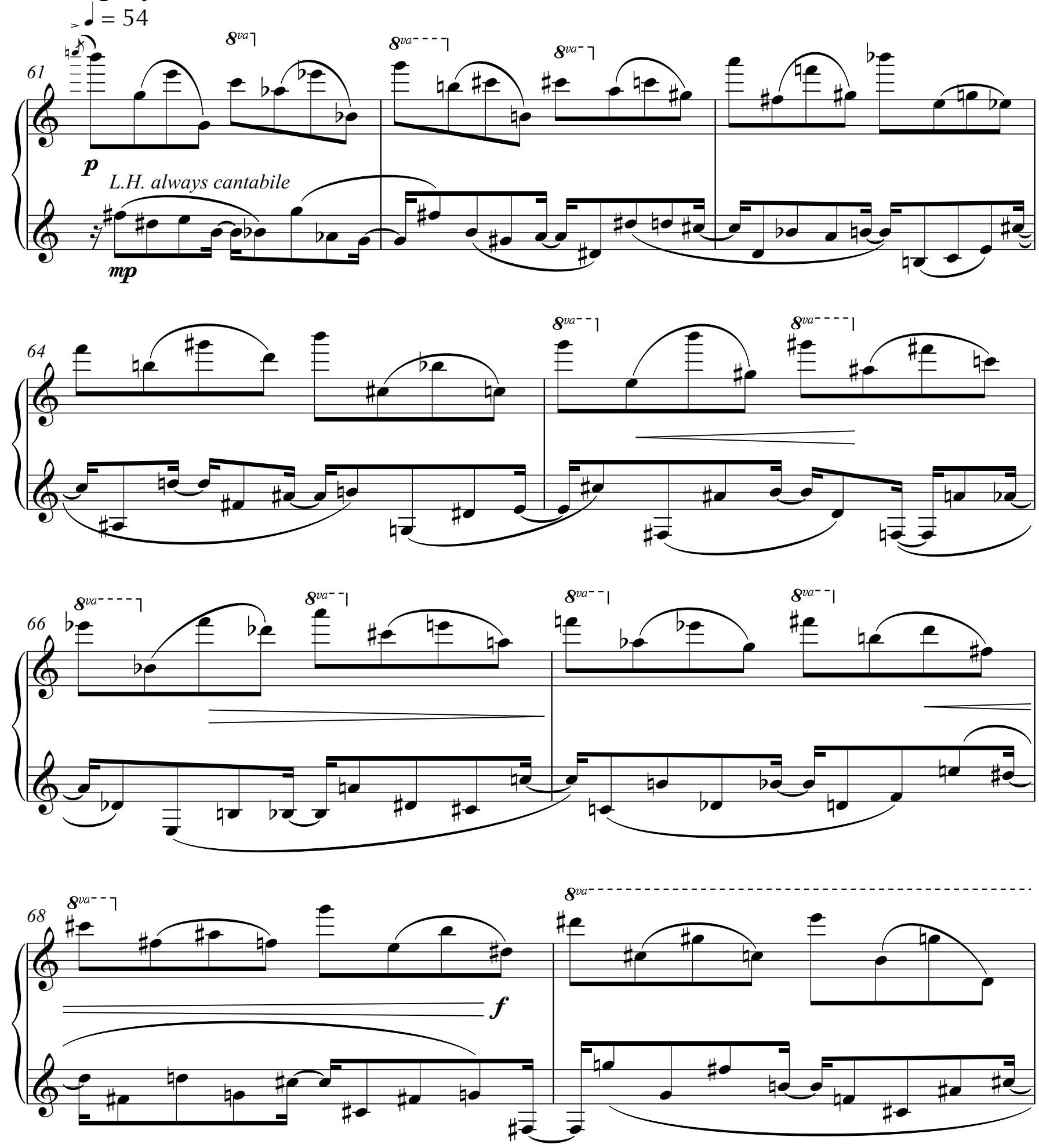

rall.

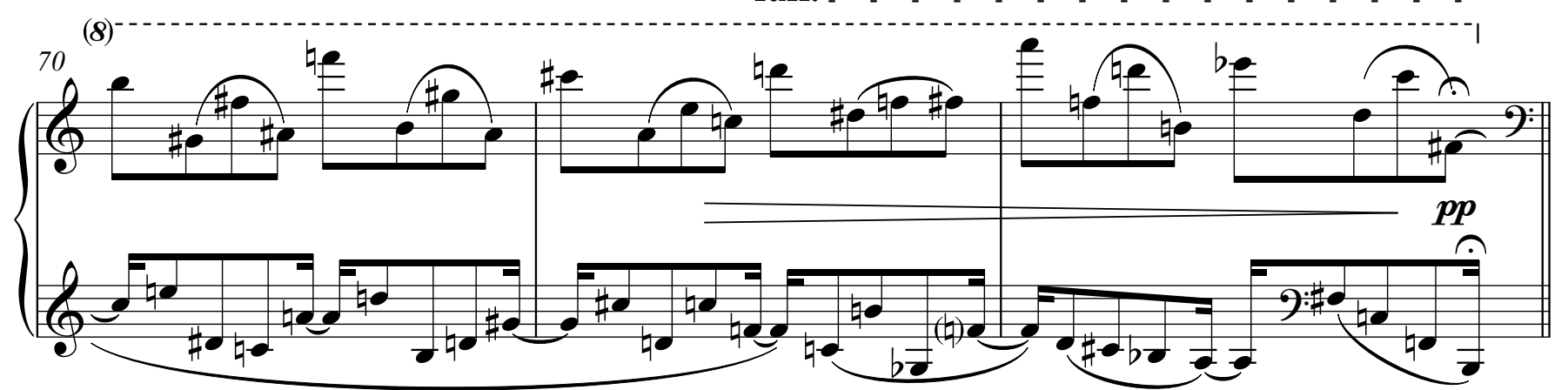


and faster again
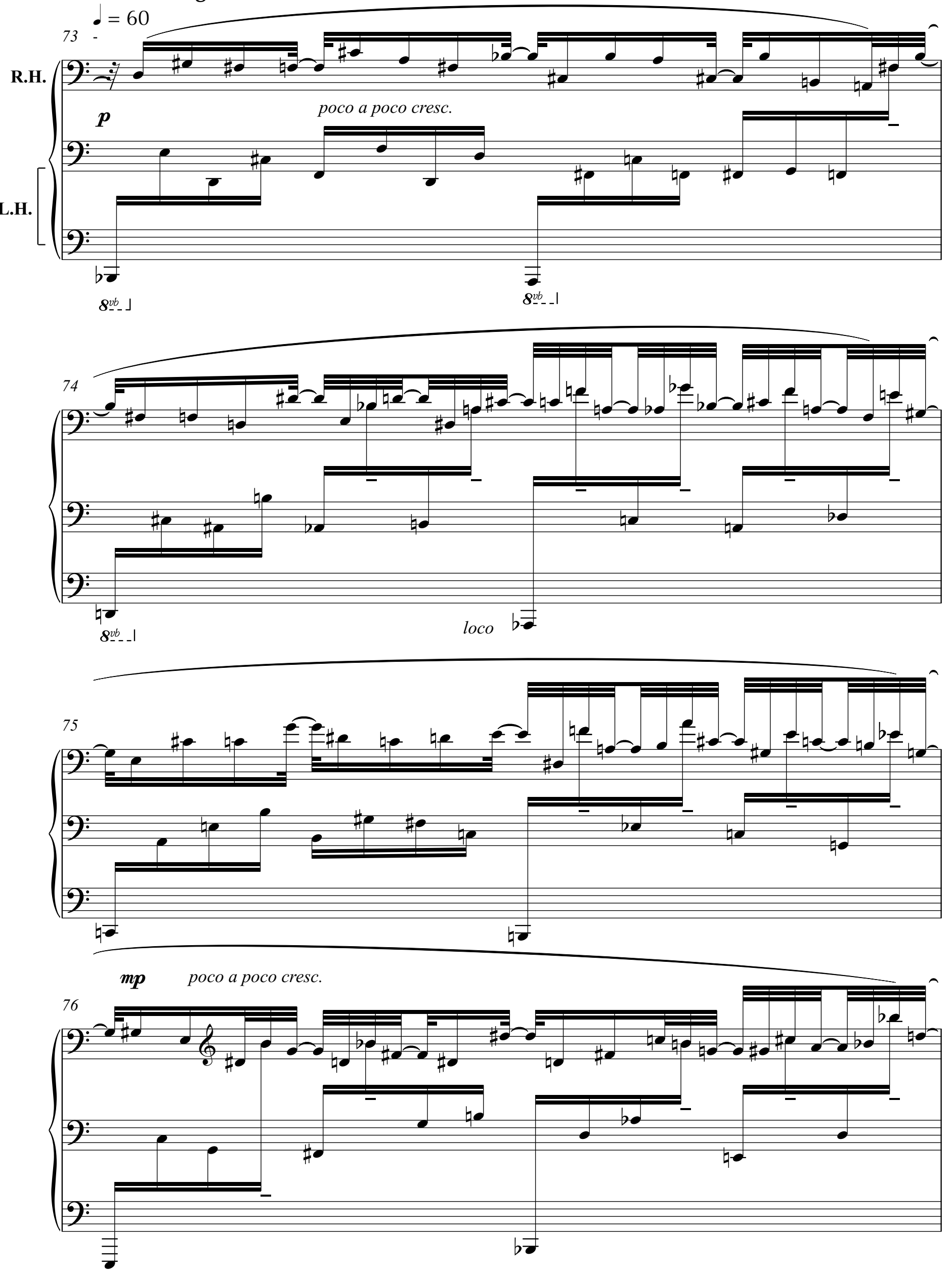
7
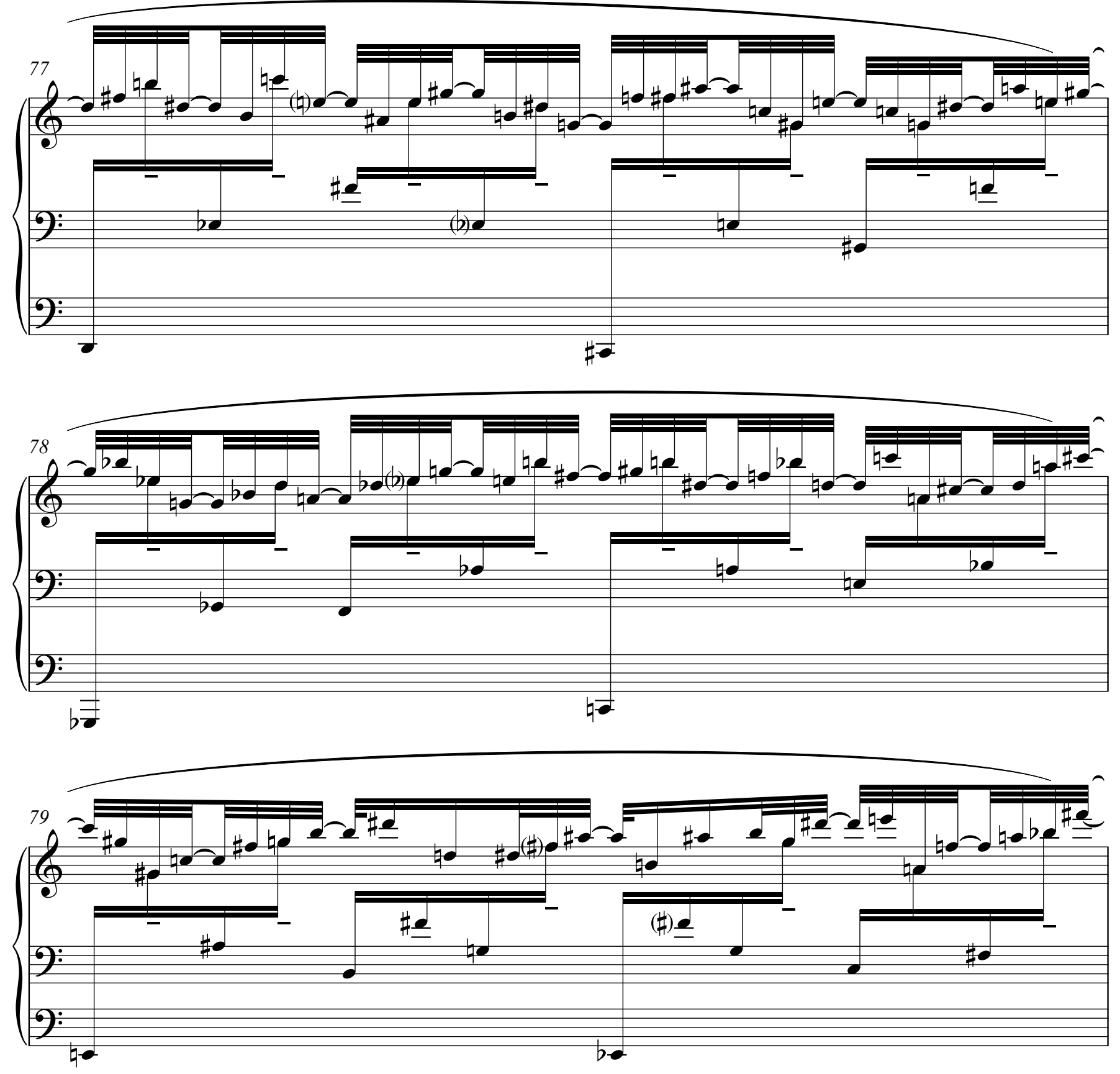

mf poco a poco cress.

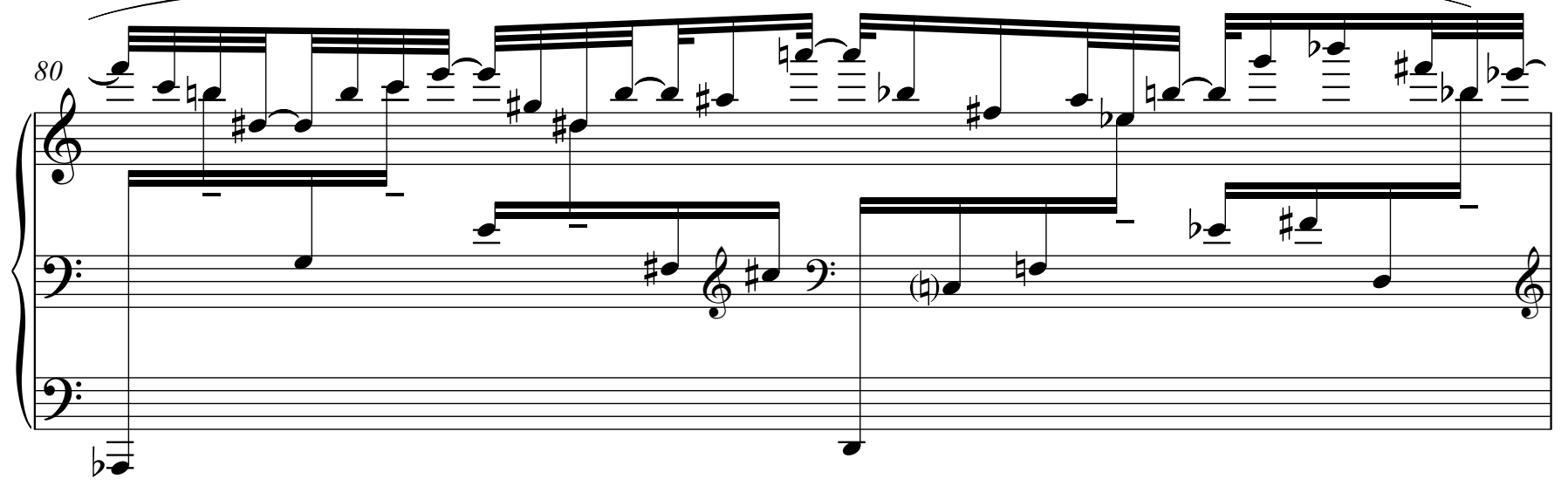



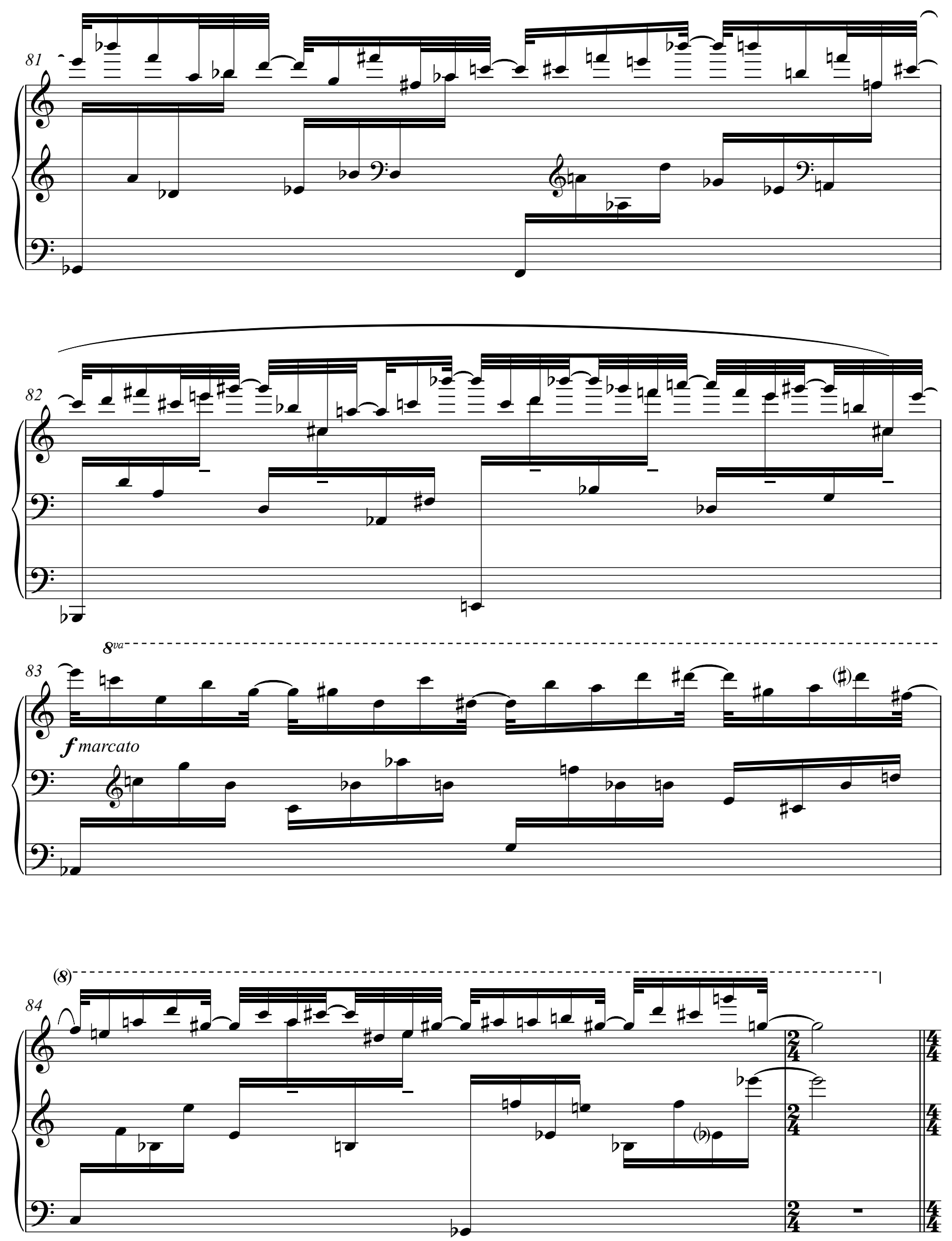
Veloce $\bullet=76$

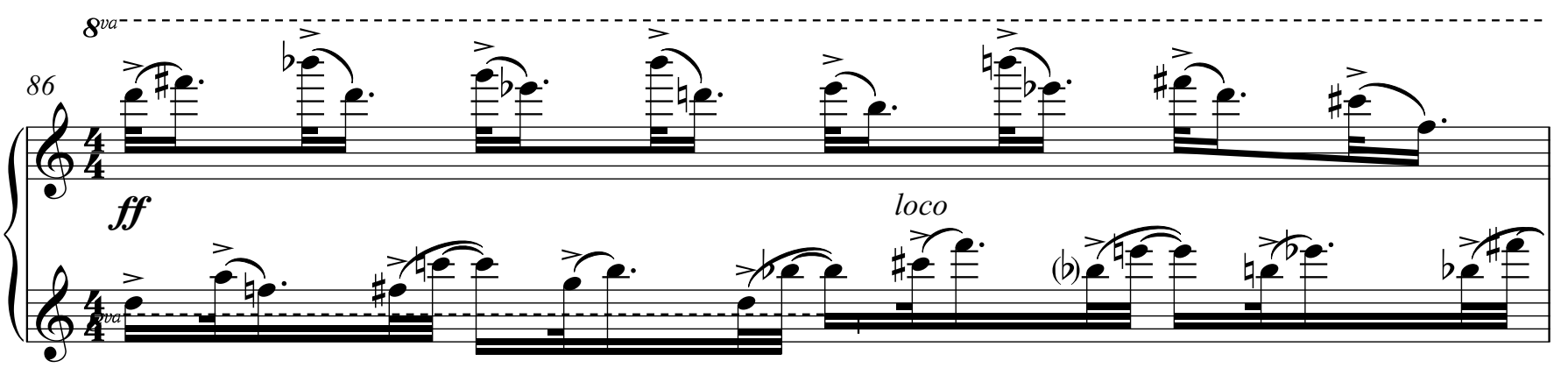

(8)

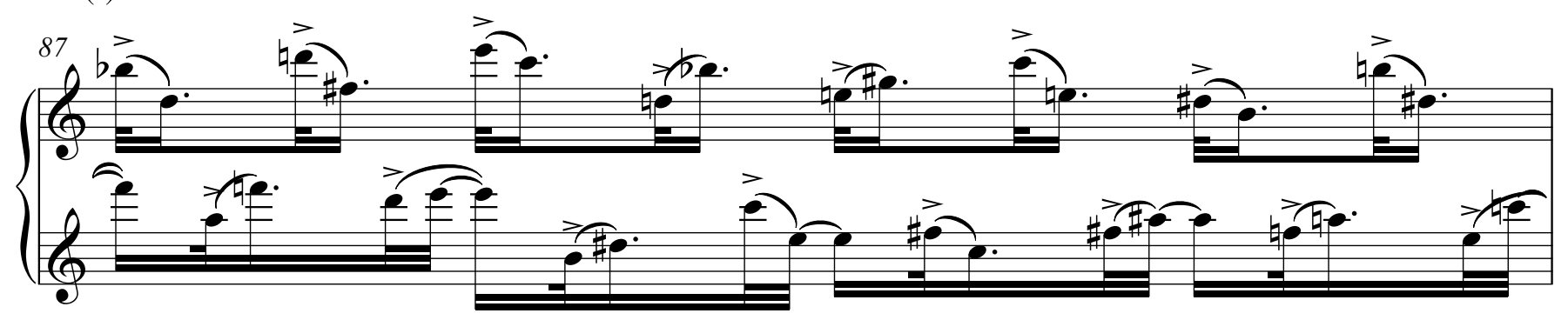

$(8)^{-}$

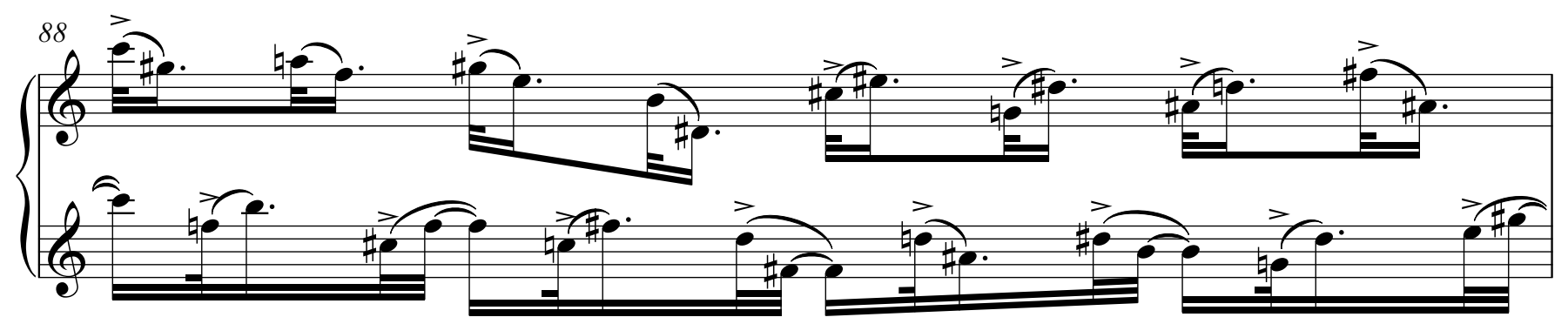

$(8)^{-}$

$\left\{\begin{array}{lllll}89 \\ 0\end{array}\right.$

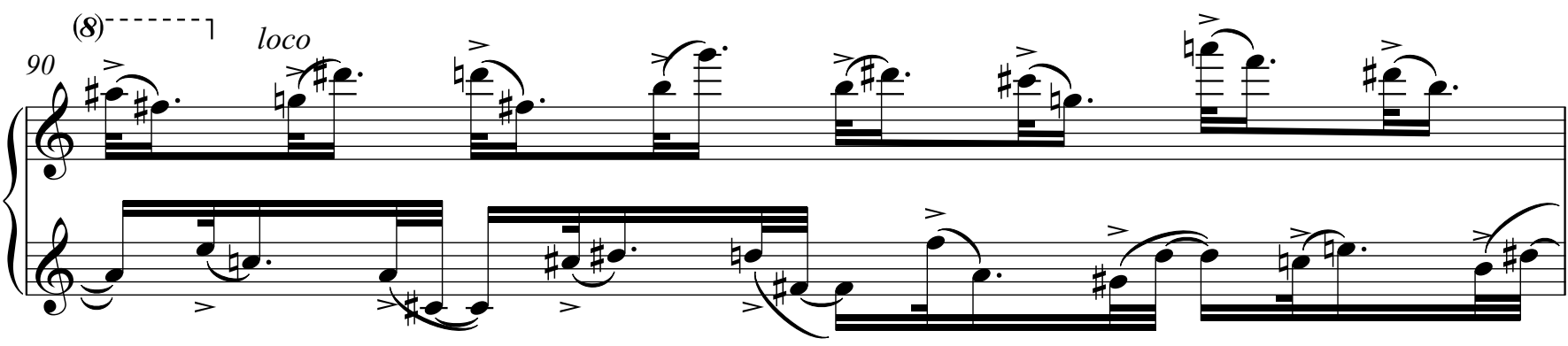

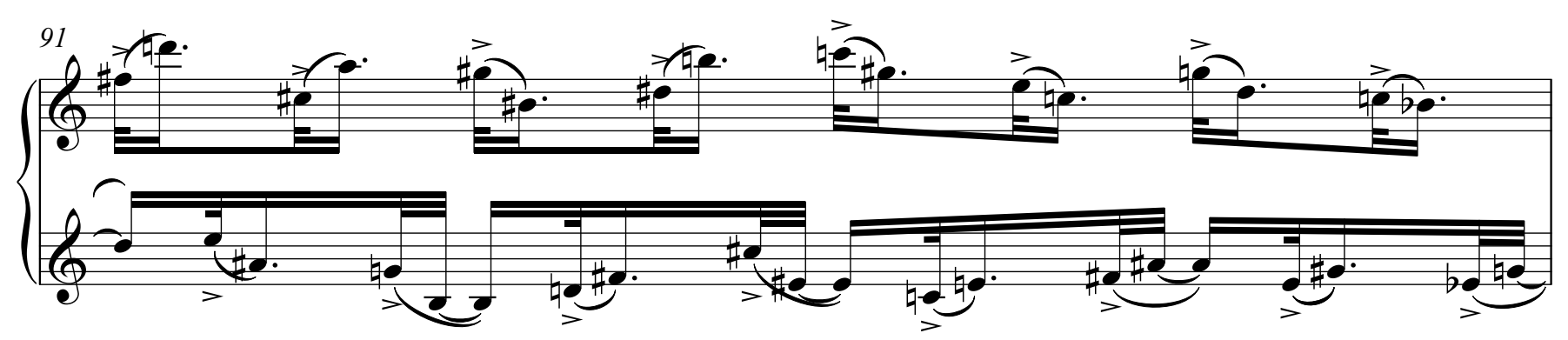




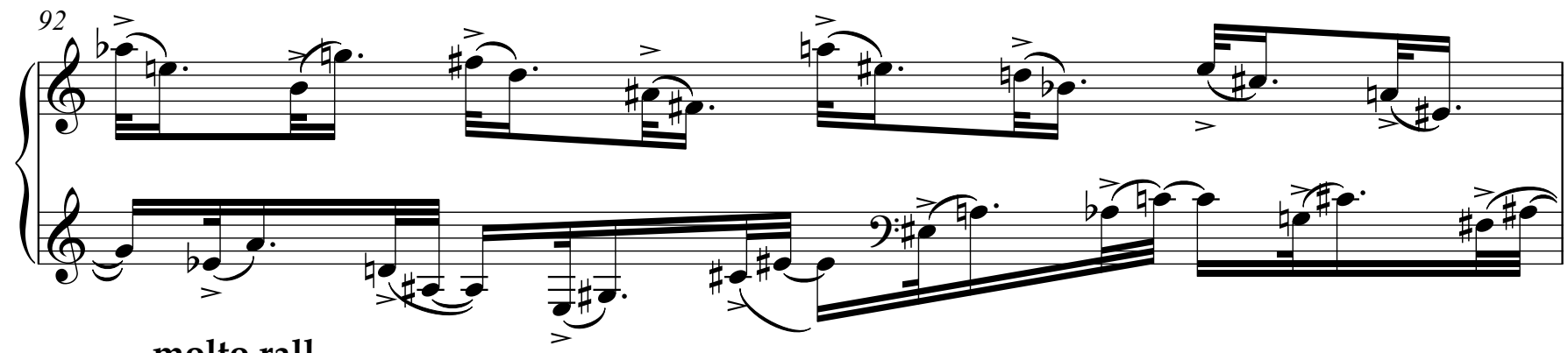
molto rall.
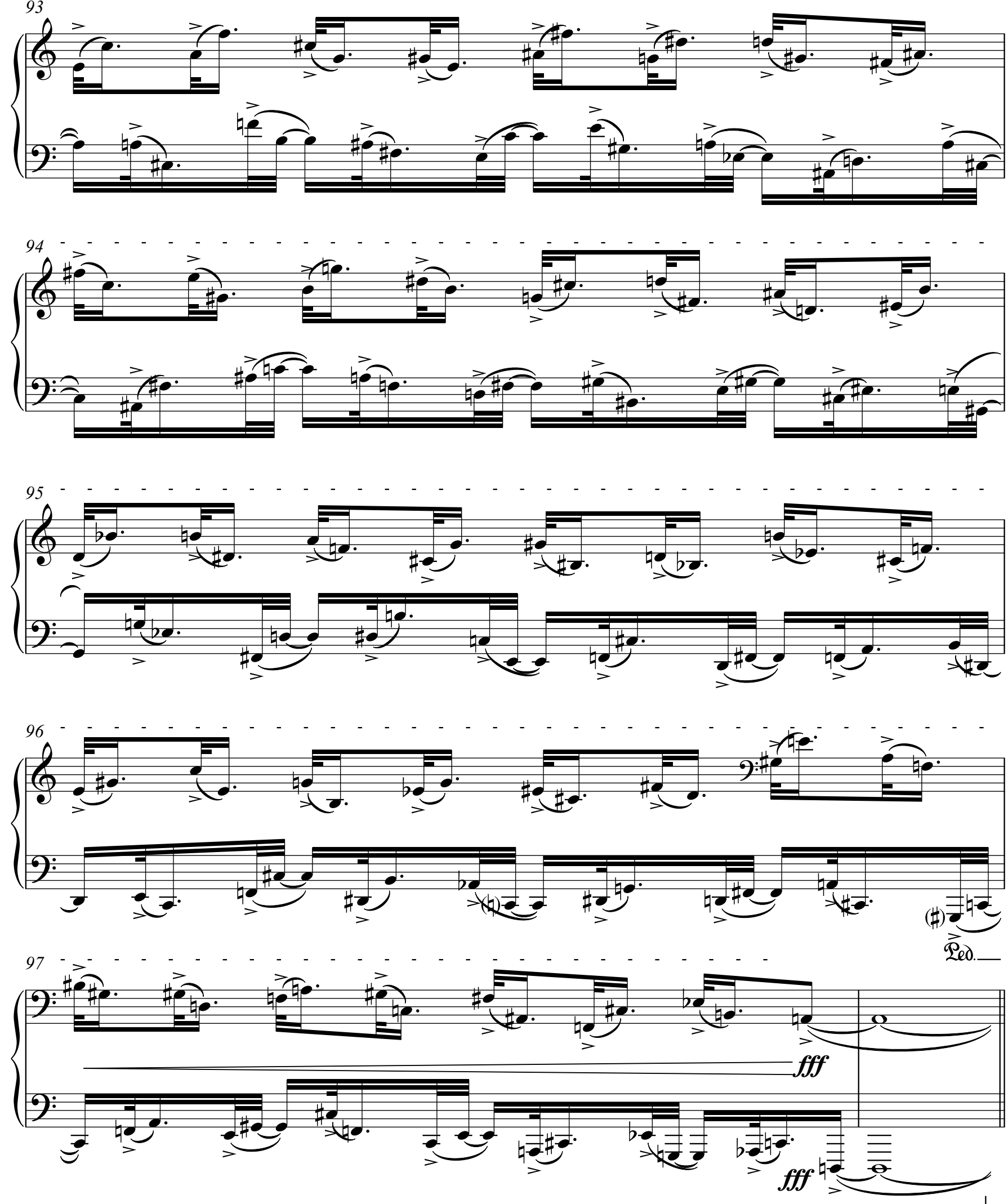
Suddenly calm
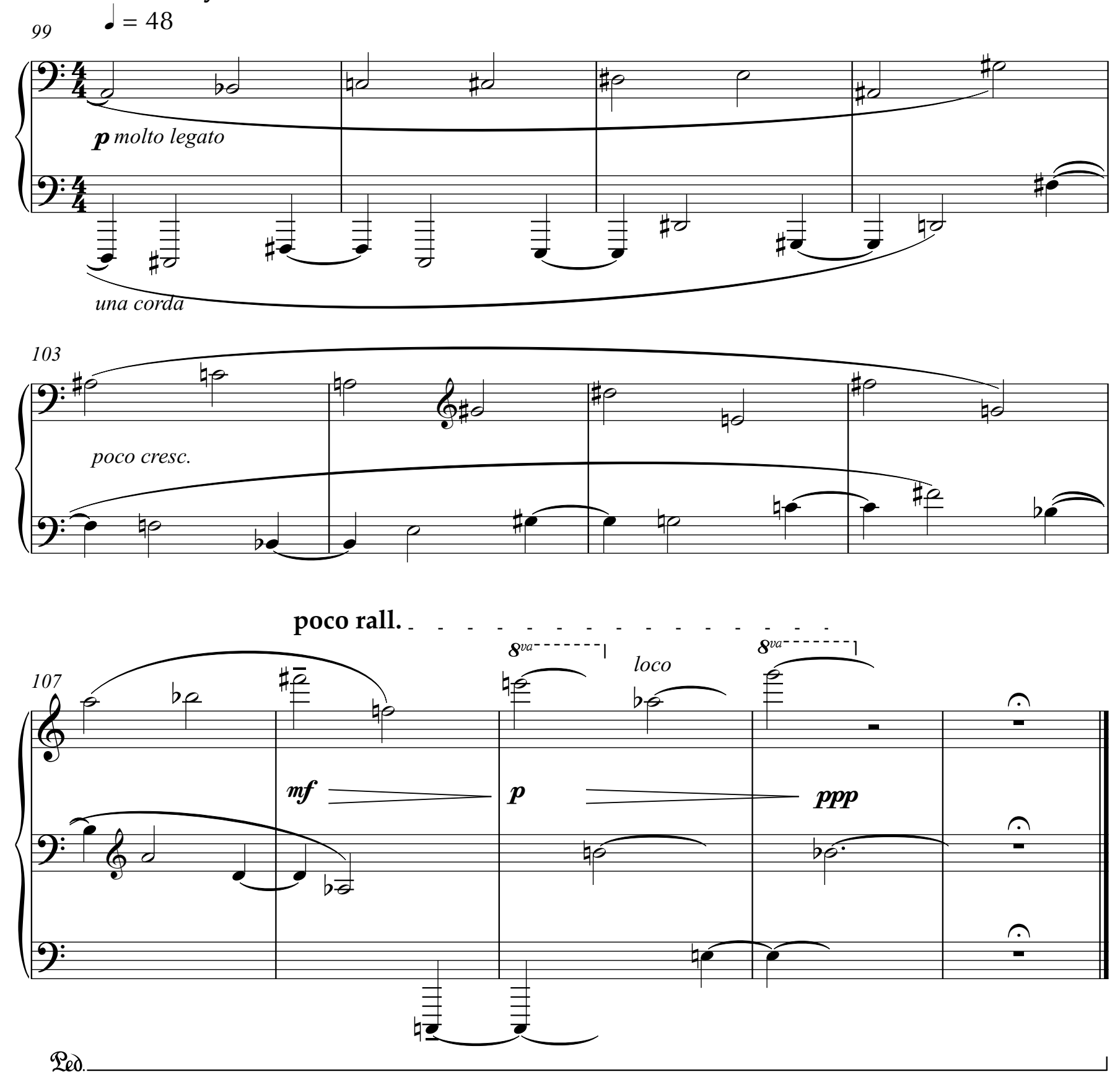